\title{
Cost-effectiveness of colorectal cancer screening in Ukraine
}

\author{
Nelya Melnitchouk ${ }^{1 *}$ D, Djøra I. Soeteman², Jennifer S. Davids ${ }^{3}$, Adam Fields' ${ }^{1}$, Joshua Cohen ${ }^{4}$, Farzad Noubary ${ }^{4}$, \\ Andrey Lukashenko ${ }^{5}$, Olena O. Kolesnik ${ }^{5}$ and Karen M. Freund ${ }^{6}$
}

\begin{abstract}
Background: Colorectal cancer is one of the most common cancers worldwide and is associated with high mortality when detected at a later stage. There is a paucity of studies from low and middle income countries to support the cost-effectiveness of colorectal cancer screening. We aim to analyze the cost-effectiveness of colorectal cancer screening compared to no screening in Ukraine, a lower-middle income country.

Methods: We developed a deterministic Markov cohort model to assess the cost-effectiveness of three colorectal cancer screening strategies [fecal occult blood test (FOBT) every year, flexible sigmoidoscopy with FOBT every 5 years, and colonoscopy every 10 years] compared to no screening. We modeled outcomes in terms of cost per qualityadjusted life-years (QALYS) over a lifetime time horizon. We performed sensitivity analyses on treatment adherence, test characteristics and costs. Analyses were conducted from the perspective of the Ministry of Health of Ukraine.

Results: The base-case lifetime cost-effectiveness analysis showed that all three screening strategies were cost saving compared to no screening, and among the three strategies, colonoscopy every 10 years was the dominant strategy compared to no screening with standard adherence to treatment. When decreased adherence to treatment was modeled, colonoscopy every 10 years was the most cost-effective strategy with an incremental cost-effectiveness ratio of $\$ 843$ per QALY compared with no screening.

Conclusion: Our findings indicate that colorectal cancer screening can save money and improve health compared to no screening in Ukraine. Colonoscopy every 10 years is superior to the other screening modalities evaluated in this study. This knowledge can be used to concentrate efforts on developing a national screening program in Ukraine.
\end{abstract}

\section{Background}

The incidence of colorectal cancer (CRC) is increasing worldwide, making it the third most common cancer in men and the second most common in women [1,2]. Mortality from CRC increases with advancing stage, with a significant drop in 5-year survival for stage IV disease. Mortality also correlates with the country's gross domestic product (GDP), with higher mortality rates in countries with lower GDP $[1,3]$. Similarly, the cost of colon cancer care depends on the stage at presentation, with costs including only surgery and surveillance for patients

\footnotetext{
*Correspondence: nmelnitchouk@bwh.harvard.edu

1 Department of Surgery, Center for Surgery and Public Health, Brigham and Women's Hospital/Harvard Medical School, 75 Francis St, Boston, MA 02115, USA

Full list of author information is available at the end of the article
}

with early disease, but adds the cost of chemotherapy and/or radiation therapy for patients with more advanced disease [4]. The cost of chemotherapy can be prohibitive in low and middle income countries (LMIC) [5], while in these settings, the cost of surgery and surveillance can be manageable, given the reliance on local resources, including a physician workforce able to provide screening and treatment services, and inpatient hospital facilities available to provide care.

CRC is a perfect candidate for screening. Most CRCs develop from a precursor lesion, an adenomatous polyp, over a course of approximately 10 years [2]. Screening not only identifies CRC at an early stage but also can prevent the disease by identifying the precursor lesion that can be removed before it develops into cancer. Further supporting the potential benefits of CRC screening is the

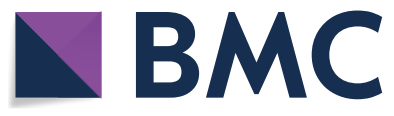

(c) The Author(s) 2018. This article is distributed under the terms of the Creative Commons Attribution 4.0 International License (http://creativecommons.org/licenses/by/4.0/), which permits unrestricted use, distribution, and reproduction in any medium, provided you give appropriate credit to the original author(s) and the source, provide a link to the Creative Commons license, and indicate if changes were made. The Creative Commons Public Domain Dedication waiver (http://creativecommons.org/ publicdomain/zero/1.0/) applies to the data made available in this article, unless otherwise stated. 
high incidence of CRC, its long preclinical and precancerous period, and the availability of treatment.

Multiple studies have demonstrated that CRC screening is cost effective in high-income countries with incremental cost-effectiveness ratios (ICERs) ranging from $\$ 611$ to $\$ 103,000$ per quality-adjusted life-year (QALY) [6-10]. In LMIC, however, there is a paucity of studies evaluating the cost-effectiveness of CRC screening. Ukraine is an example of a LMIC with reasonable local resources in terms of available physicians and infrastructure, but limited financial means. Currently, the country does not have an established CRC screening program and $35 \%$ of CRC patients die within a year of diagnosis, likely reflecting the late stage at diagnosis and lack of financial resources to make costly chemotherapy agents available to all patients [11]. In fact, $25 \%$ of patients with CRC in Ukraine do not receive any treatment [8].

The aim of this study was to assess the cost-effectiveness of various CRC screening strategies including no screening to inform the decision if implementing a screening program in Ukraine is cost-effective. We incorporated clinical and economic data from the published literature in a simulation model to compare the different CRC screening strategies over a lifetime time horizon in terms of costs per QALY.

\section{Methods}

\section{Model overview}

We modified a model structure of a previously-published Markov cohort model [7] to evaluate the cost-effectiveness of implementing a national screening protocol in Ukraine compared with the current situation of no screening (Fig. 1). We assumed that screening started for 50-year-old members of the population with an average cancer risk and that screening continued to the age of 75 years. We adopted the third party perspective and modeled clinical events and costs over a lifetime time horizon. The cycle length of the Markov model was 1-year. We implemented the model in TreeAge Pro (TreeAge Software Inc, Williamston, MA) and audited calculations via MS Excel. Table 1 lists the model parameters and key assumptions.

Persons entered the model at the age of 50 and could reside in any of the following health states: normal mucosa, low risk polyp $(<1 \mathrm{~cm})$, high-risk polyp $(>1 \mathrm{~cm})$, preclinical CRC (localized, regional, and disseminated). They could transition between states in yearly time intervals, stay in their current state or develop clinical CRC (localized, regional, and disseminated). Persons could either die from cancer or from other causes or be in surveillance after treatment for colorectal cancer.

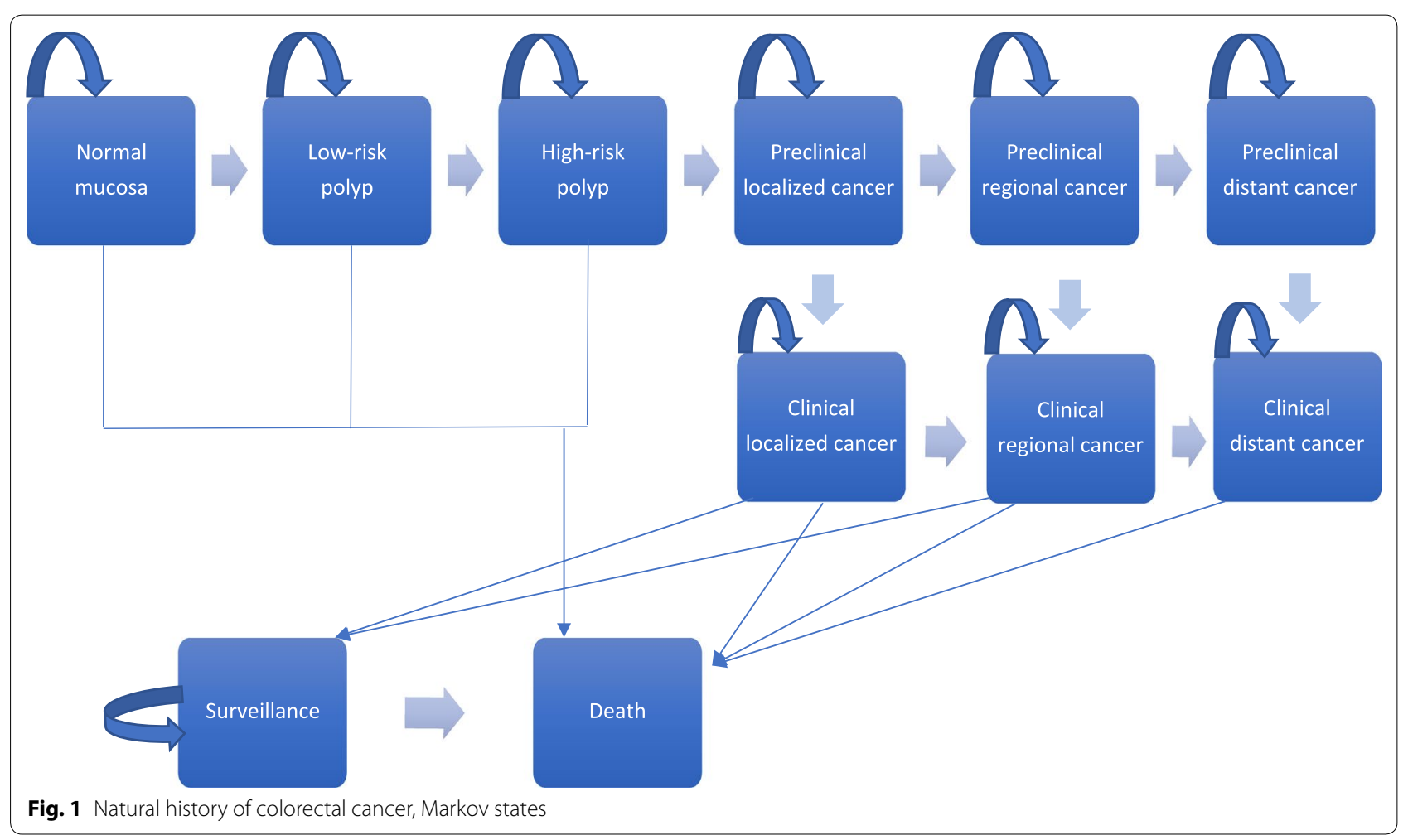


Table 1 Model parameters and assumptions

\begin{tabular}{|c|c|c|c|}
\hline & Base case & Range (SD) & References \\
\hline \multicolumn{4}{|l|}{ Natural history } \\
\hline \multirow[t]{3}{*}{ Prevalence of low risk polyp (based on age) } & At age $50,0.2$ & $0.15-0.25$ & {$[15-17]$} \\
\hline & At age $60,0.4$ & $0.35-0.45$ & \\
\hline & At age $70,0.5$ & $0.45-0.55$ & \\
\hline \multirow[t]{4}{*}{ Prevalence of high risk polyp (based on age) } & At age $50,0.05$ & $0.03-0.07$ & {$[15-17]$} \\
\hline & At age $60,0.09$ & $0.07-0.12$ & \\
\hline & At age $70,0.16$ & $0.14-0.18$ & \\
\hline & At age $80,0.21$ & $0.20-0.22$ & \\
\hline Prevalence of preclinical early CRC at age 50 & 0.0024 & $0.002-0.0026$ & {$[15-17]$} \\
\hline Prevalence of preclinical regional $C R C$ at age 50 & 0.0012 & $0.0008-0.0014$ & {$[15-17]$} \\
\hline Prevalence of preclinical distant CRC at age 50 & 0.0004 & $0.0003-0.0005$ & {$[15-17]$} \\
\hline \multicolumn{4}{|l|}{ Yearly transition probabilities } \\
\hline \multirow[t]{5}{*}{ Normal mucosa to low risk polyp (based on age) } & At age $50,0.00836$ & $\pm 10 \%$ & {$[15-17]$} \\
\hline & At age 55, 0.0099 & & \\
\hline & At age $60,0.01156$ & & \\
\hline & At age $65,0.0133$ & & \\
\hline & At age $70,0.01521$ & & \\
\hline Low risk polyp to high risk polyp & 0.036 & $0.025-0.047$ & {$[15-17]$} \\
\hline High risk polyp to preclinical local cancer & 0.042 & $0.03-0.051$ & {$[15-17]$} \\
\hline Preclinical local cancer to preclinical regional cancer & 0.17 & $0.12-0.22$ & {$[15-17]$} \\
\hline Preclinical regional to preclinical distal & 0.10 & $0.05-0.15$ & [15-18] \\
\hline Preclinical local to clinical local & 0.17 & $0.12-0.23$ & [15-18] \\
\hline Preclinical regional to clinical regional & 0.21 & $0.16-0.26$ & [15-18] \\
\hline Preclinical distant to clinical distal & 1 & N/A & [15-18] \\
\hline \multicolumn{4}{|l|}{ Cancer mortality 5 year standard adherence } \\
\hline Localized & 0.1 & N/A & [19] \\
\hline Regional & 0.35 & N/A & [19] \\
\hline Disseminated & 0.92 & N/A & [19] \\
\hline \multicolumn{4}{|l|}{ Adherence with screening guidelines } \\
\hline FOBT & 0.75 & $0.4-0.8$ & [20-22] \\
\hline Sigmoidoscopy with FOBT & 0.75 & $0.4-0.8$ & {$[20-22]$} \\
\hline Colonoscopy & 0.8 & $0.4-0.8$ & [20-22] \\
\hline Colonoscopy after positive screening test & 0.84 & $0.4-0.9$ & {$[20-22]$} \\
\hline \multicolumn{4}{|l|}{ Test characteristics } \\
\hline FOBT sensitivity low risk polyp & 0.03 & $0.01-0.1$ & {$[23,24]$} \\
\hline FOBT sensitivity high risk polyp & 0.34 & $0.2-0.5$ & {$[23,24]$} \\
\hline FOBT sensitivity cancer & 0.72 & $0.5-0.85$ & {$[23,24]$} \\
\hline FOBT specificity & 0.91 & $0.7-0.96$ & {$[23,24]$} \\
\hline Colonoscopy/sigmoidoscopy sensitivity low risk polyp & 0.92 & $0.75-0.95$ & {$[25-28]$} \\
\hline Colonoscopy/sigmoidoscopy sensitivity high risk polyp & 0.97 & $0.75-0.97$ & [25-28] \\
\hline Colonoscopy/sigmoidoscopy sensitivity cancer & 0.93 & $0.75-0.95$ & {$[25-28]$} \\
\hline Colonoscopy/sigmoidoscopy specificity & 1 & N/A & [25-28] \\
\hline Probability of negative sigmoidoscopy and proximal neoplasm & 0.21 & $0.11-0.31$ & {$[25-28]$} \\
\hline \multicolumn{4}{|l|}{ Complications } \\
\hline Death from colonoscopic perforation & 0.012 & $0.01-0.02$ & {$[30]$} \\
\hline Perforation from diagnostic colonoscopy & 0.0008 & $0.0006-0.005$ & {$[30]$} \\
\hline \multicolumn{4}{|l|}{ QALY } \\
\hline Local/regional cancer & 0.7 & $0.52-0.9$ & {$[31]$} \\
\hline Disseminated cancer & 0.25 & $0.15-0.35$ & [31] \\
\hline
\end{tabular}


Table 1 (continued)

\begin{tabular}{llll}
\hline & Base case & Range (SD) & References \\
\hline Costs (US \$) & & & \\
Cost of colonoscopy & 100 & $30-300$ & Expert opinion \\
Cost of FOBT & 8 & $5-20$ & Manufacturer price \\
Cost of sigmoidoscopy & 20 & $10-100$ & Expert opinion \\
Cost of treating colonoscopic perforation & 500 & $200-1000$ & Expert opinion \\
Cost of local cancer treatment & 500 & $200-1500$ & Expert opinion \\
Cost of regional cancer treatment & 9000 & $500-15,000$ & {$[32]$} \\
Cost of disseminated cancer treatment & 20,000 & $5000-25,000$ & {$[32]$} \\
Cost of surveillance & 200 & $100-500$ & Expert opinion \\
\hline
\end{tabular}

$C R C$ colorectal cancer, FOBT fecal occult blood test, $Q A L Y$ quality adjusted life years

\section{Natural history}

We used data from the published literature to obtain estimates of the prevalence of the polyps and age-specific transition probabilities [12-19] (Table 1). We adjusted the estimates of prevalence of the polyps to the incidence based on age of CRC in Ukraine. We used 2013 Ukrainian life tables from the World Health Organization for background mortality. We estimated stage-specific CRC mortality with treatment using US data from the Surveillance, Epidemiology and End Results (SEER) database, given that the data on CRC mortality in Ukraine doesn't represent mortality with treatment since large proportion of patients to not receive cancer specific treatment [19]. We used the National Cancer Registry of Ukraine database to estimate current Ukrainian CRC incidence, mortality, and treatment adherence [8].

\section{Screening and treatment effectiveness}

In this analysis we included three different screening strategies that would be reasonable to implement in a LMIC with an established medical infrastructure: (1) yearly FOBT, followed by confirmatory colonoscopy if positive; (2) flexible sigmoidoscopy every 5 years with FOBT yearly, also followed by colonoscopy if positive; (3) colonoscopy every 10 years [20-30]. Data on detection rate of these three screening scenarios, data on adherence with screening, screening complications rates, and utilities were obtained from screening studies conducted in Western countries and are displayed in Table 1 [17-22, 31]. We assumed no polyp removal during sigmoidoscopy, but instead that polyps are removed as part of a full colonoscopy procedure.

\section{Costs}

We calculated costs from the third party payer perspective, in this case, the Ukraine Ministry of Health, and included direct treatment and screening costs. Indirect costs that are incurred by the patients such as transportation and lost productivity were not included. Screening costs were based on the manufacturer's price for FOBT and on prices charged by private medical institutions in Ukraine (Table 1). We estimated treatment costs based on chemotherapy third party prices that the Ministry of Health of Ukraine pays for medications, as documented on the Ministry's website [32]. We assumed doses appropriate for a $70 \mathrm{~kg}$ male and calculated costs for regional cancer [5-fluorouracil + Leukovorin + Oxaliplatin (FOLFOX for 12 cycles)] and disseminated cancer (FOLFOX + Bevacizumab for 12 cycles) regimens. We obtained surgical and radiation therapy costs from private clinics and modified them to reflect what would be reasonable in the public sector based on expert opinion from personnel at the National Cancer Institute of Ukraine (Personal communication with Dr. Kolesnik and Dr. Lukashenko). All costs were translated to 2012 US dollars.

\section{Cost-effectiveness analysis}

We compared the four strategies by conducting a costeffectiveness analysis. Strategies that were more costly and less effective than an alternative option were considered dominated and therefore excluded from the final cost-effectiveness calculations. For the remaining strategies, the incremental cost-effectiveness ratio (ICER) was calculated as the additional costs divided by the additional health benefit of the strategy compared with the next best non-dominated strategy. The most costeffective strategy was then identified by comparing the ICERs against the willingness-to-pay (WTP) threshold for an additional QALY. We chose a WTP threshold of three times the per-capita gross domestic product (GDP), which is \$11,700 US dollars per QALY (Ukraine's annual per capita GDP is 3900 US dollars) [30]. The most costeffective option was the strategy with the highest ICER 
below this WTP threshold. We discounted future costs and effectiveness at an annual rate of $3 \%$, consistent with recommendations in the field of health economics [30].

\section{Sensitivity analyses}

We conducted sensitivity analyses to determine the impact of different variables on the cost-effectiveness results. We tested the uncertain variables in the model in one-way sensitivity analyses. The variables that we varied were adherence with screening, test characteristics, rate of complications, and costs of screening strategies and treatment. The ranges were chosen based on existing literature for variation on natural history, test characteristics, and adherence parameters and based on expert opinion for cost parameters (Table 1). We conducted two and three-way sensitivity analyses on the assumptions that had the greatest effects on the cost-effectiveness results identified in the one-way sensitivity analyses.

\section{Results \\ Model validation}

Figure 2 shows the annual incidence of CRC per 100,000 persons by age for the model predictions and data from the National Cancer Registry of Ukraine in 2013-2014. The figure illustrates that the observed incidences were very similar to what the model predicted.

\section{Cost-effectiveness analysis}

The lifetime costs, effects, and cost-effectiveness of the different scenarios are presented in Table 2. All screening programs were less costly and more effective compared with the no screening program. FOBT yearly, sigmoidoscopy with FOBT every 5 years, and no screening were

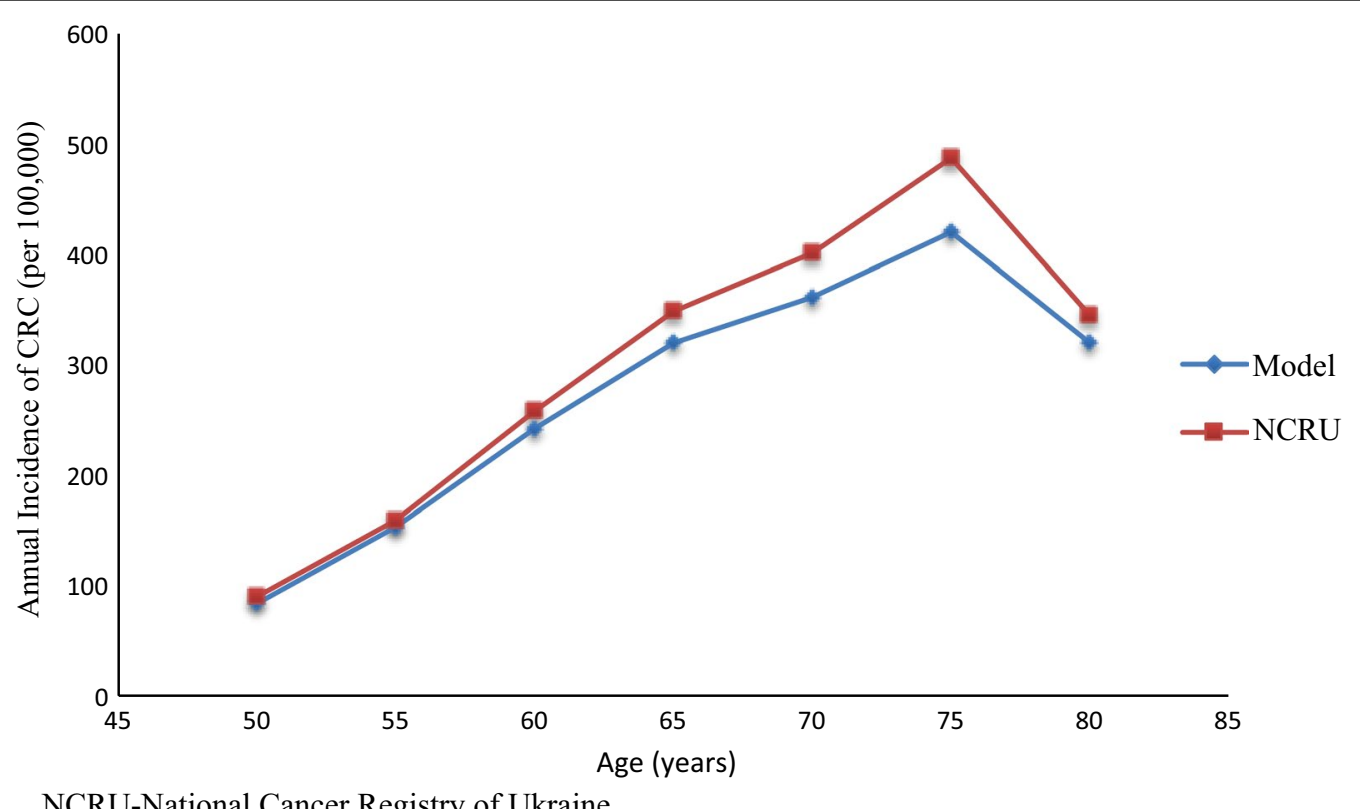

NCRU-National Cancer Registry of Ukraine

Fig. 2 Model calibration: incidence based on age. NCRU National Cancer Registry of Ukraine

Table 2 Costs, effects, and cost effectiveness of colorectal cancer screening programs over a lifetime horizon in the Ukraine

\begin{tabular}{llllllc}
\hline Strategy & $\begin{array}{l}\text { Mean cost } \\
(\mathbf{2 0 1 2} \text { US\$) }\end{array}$ & $\begin{array}{l}\text { Mean effects } \\
\text { (QALY) }\end{array}$ & $\begin{array}{l}\text { Incremental cost } \\
\text { (2012 US\$) }\end{array}$ & $\begin{array}{l}\text { Incremental effects } \\
\text { (QALY) }\end{array}$ & ICER & Mortality decrease \\
\hline $\begin{array}{l}\text { Colonoscopy every } \\
\text { 10 years }\end{array}$ & 235 & 14.307 & N/A & N/A & Dominant & $73 \%$ \\
$\begin{array}{l}\text { FOBT yearly } \\
\begin{array}{l}\text { Sigmoidoscopy every } \\
5 \text { years with FOBT }\end{array}\end{array}$ & 247 & 14.295 & 13 & -0.013 & Dominated & $61.6 \%$ \\
\begin{tabular}{l} 
No screening \\
\hline
\end{tabular} & 404 & 14.300 & 21 & -0.008 & Dominated & $64 \%$ \\
\end{tabular}

US United States, QALY quality adjusted life years, ICER incremental cost effectiveness ratios, FOBT fecal occult blood test 
all more costly and less effective than colonoscopy every 10 years (Fig. 3).

Mortality estimates (Table 2) demonstrate benefits with all three screening scenarios compared to no screening, with colonoscopy every 10 years producing the greatest benefits in terms of decreased mortality. Colonoscopy screening every 10 years decreased colon cancer mortality by $73 \%$ compared to no screening. FOBT decreased mortality by $61.6 \%$ and flexible sigmoidoscopy with FOBT decreased mortality by $64 \%$.

\section{Sensitivity analyses}

The results of the one-way sensitivity analyses show that the variable cost of colonoscopy and decreased compliance with colonoscopy have an impact on the most optimal screening scenario. The optimal screening scenario changes from colonoscopy every 10 years to sigmoidoscopy with FOBT when the costs of colonoscopy exceed the threshold value of $\$ 236$ and the probability of compliance with colonoscopy falls below the threshold value of 0.66 . The cost of cancer treatment or surveillance in the range tested did not impact the preferred strategy (Fig. 4).
In the scenario with decreased adherence to treatment, currently present in Ukraine, all the screening strategies were still cost effective, and the colonoscopy was still the most cost effective strategy with an incremental cost effectiveness ratio of $\$ 843$.

\section{Discussion}

Using a Markov cohort model, we compared the costeffectiveness of three screening strategies compared to no screening starting in a 50 year-old population from the third party payer perspective. Our results indicate that the CRC screening strategies included in our analysis are cost saving in Ukraine compared to the current state of no national screening program. Colonoscopy every 10 years is the optimal screening program in terms of costs per QALY and decreased mortality. Results were sensitive to the cost of colonoscopy and adherence to screening. Even when we evaluated the scenario of lower adherence to cancer treatment, which is currently the situation in Ukraine, the results did not change with colonoscopy every 10 years as the preferred strategy with an ICER of $\$ 843$, which is well below the WTP threshold for health of $\$ 11,700$ per QALY.

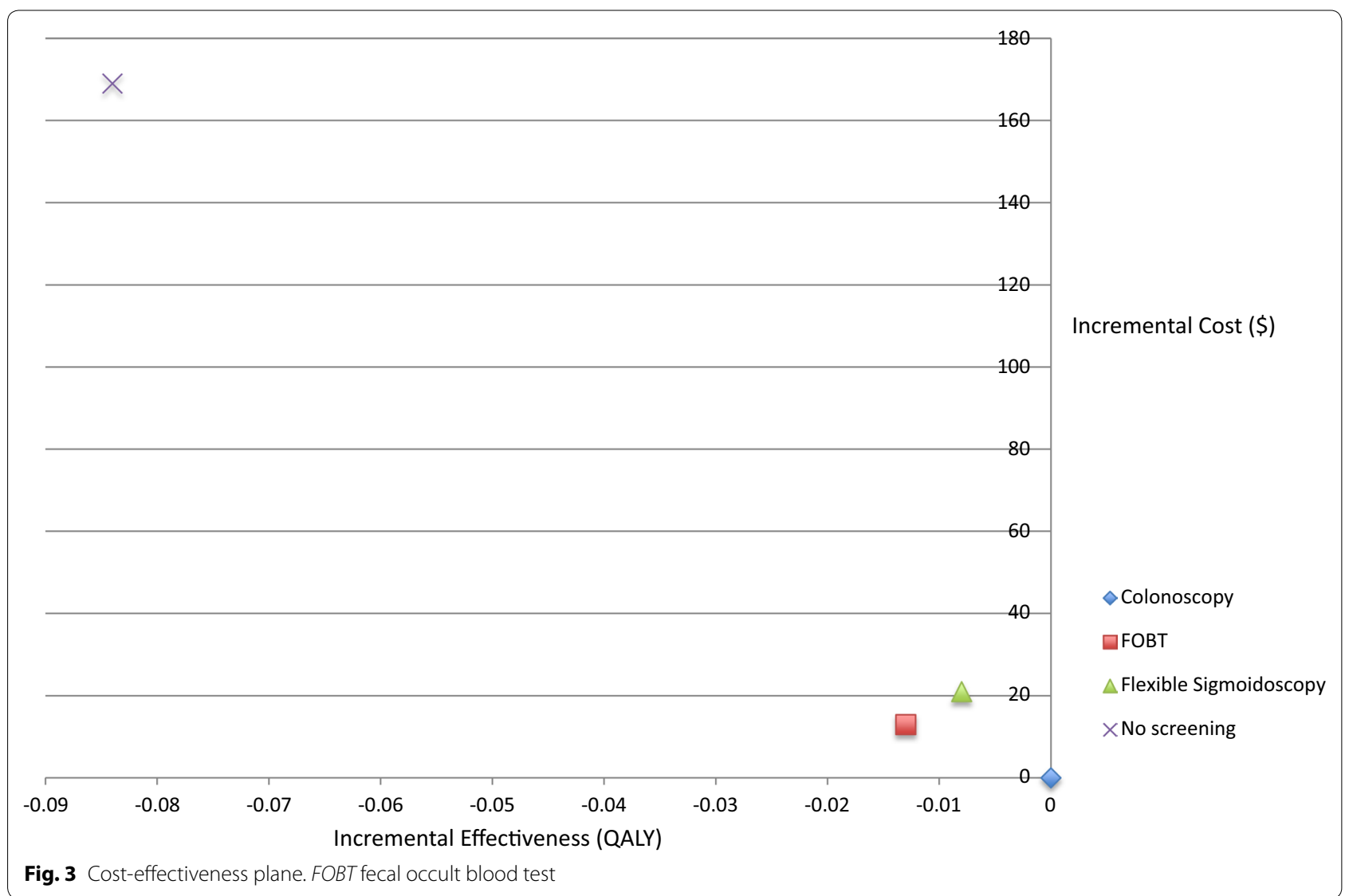


Tornado Analysis (Net Benefits)

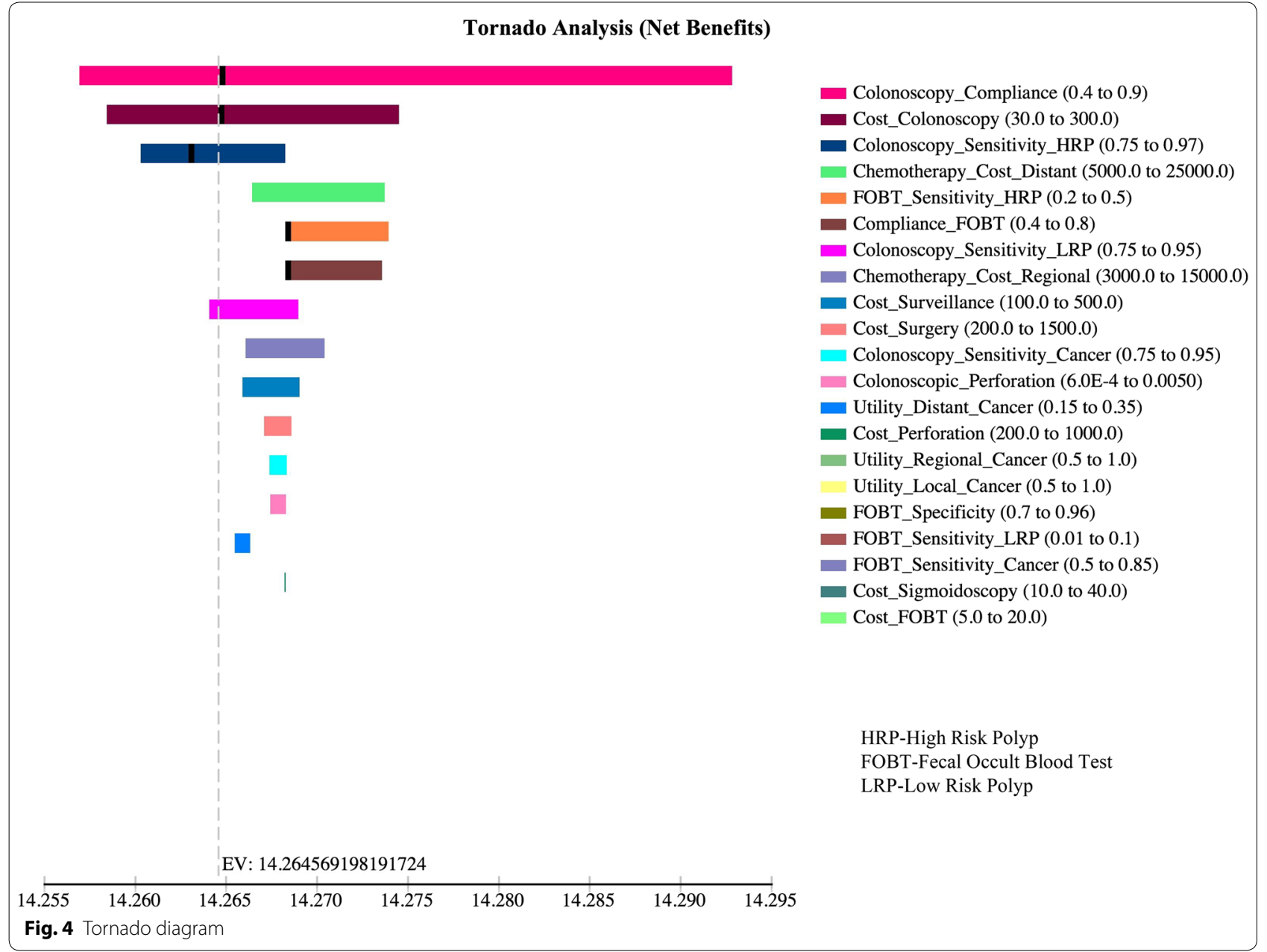

There are multiple studies from the US and highincome European countries that demonstrated the cost effectiveness of CRC screening [8, 10,33-37]. These interventions are usually reported to be cost-effective when their ICER is less than $\$ 50,000-\$ 100,000$ per QALY. Our findings are consistent with cost effectiveness studies done in the US and Europe, although most of those studies found colonoscopy or screening in general to be favorably cost-effective, whereas we found these strategies to both improve health and save money. This observation is not surprising given that the cost of colonoscopy is very low in Ukraine in contrast to the high cost of treatment of advanced stages of CRC [5].

Ukraine is similar to other countries in Central and Eastern Europe (CEE), which are characterized by significantly lower cancer survival then in Western European countries, and colorectal cancer is not an exception [38]. Less effective cancer control strategies, such as low screening rate, scarcity of screening programs, less treatment options available and cost of care among many others, have been implicated [39]. Focus on improved cancer control and prevention is of a paramount importance.

The reduction in CRC mortality with screening that we found is similar to the corresponding reductions reported by prior cost effectiveness studies, thus corroborating our model $[7,8,40]$. Given that a large proportion of the patients in Ukraine do not undergo the proper treatment for their CRC, the reduction in mortality and benefit in terms of costs and health benefits to society was even greater when low treatment adherence was considered.

Our analysis is not without limitations. The costs were calculated from the payer perspective. Taking the societal perspective, where the cost of lost productivity, cost of travel is included may be more appropriate but likely would not change the results given that colonoscopy is only performed every 10 years and other screening methods happen more frequently, with increased opportunity for societal costs. The model did not incorporate the potentially high cost of establishing a national screening program in Ukraine, including the costs of addressing adherence, public health campaigns to change attitudes, 
or other methods at the provider level to increase adherence.

To our knowledge this is the first cost-effectiveness analysis focusing on screening strategies for colorectal cancer in Ukraine and has the potential to contribute significantly to the knowledge base guiding rational decision making with respect to clinical practice and health care resource allocation [41]. If acted upon, the findings of our study may substantially improve CRC care in Ukraine and can be used to concentrate efforts on developing a national screening program. Additionally, this analysis can guide analyses in other LMIC countries with similar GDP and infrastructure.

\section{Authors' contributions}

NM was involved in study design, literature search, data collection, extraction, analysis and interpretation and writing of the report. DS, JC, FN, KF were involved in study design, data analysis, data interpretation and editing the manuscript. JD, AF, AL, OK were involved in data collection, interpretation and editing. All authors read and approved the final manuscript.

\section{Author details \\ ${ }^{1}$ Department of Surgery, Center for Surgery and Public Health, Brigham and Women's Hospital/Harvard Medical School, 75 Francis St, Boston, MA 02115, USA. ${ }^{2}$ Center for Health Decision Science, Harvard T.H. Chan School of Public Health, Boston, MA, USA. ${ }^{3}$ UMass Medical Center, Worcester, MA, USA. ${ }^{4}$ Tufts Clinical and Translational Science Institute, Boston, MA, USA. ${ }^{5}$ National Cancer Institute, Kiev, Ukraine. ${ }^{6}$ Tufts Medical Center and Tufts University School of Medicine Boston, Boston, MA, USA.}

\section{Acknowledgements}

Not applicable.

\section{Competing interests}

The authors declare that they have no competing interests.

\section{Availability of data and materials}

All data extracted from publicly available information.

\section{Consent for publication}

Not applicable.

Ethics approval and consent to participate

Not applicable.

\section{Funding}

Brigham and Women's Hospital, Department of Surgery.

\section{Publisher's Note}

Springer Nature remains neutral with regard to jurisdictional claims in published maps and institutional affiliations.

Received: 4 December 2017 Accepted: 1 June 2018 Published online: 07 June 2018

\section{References}

1. Ferlay J, et al. Estimates of worldwide burden of cancer in 2008: GLOBOCAN 2008. Int J Cancer. 2010;127(12):2893-917.

2. Global Burden of Disease Cancer, et al. Global, regional, and national cancer incidence, mortality, years of life lost, years lived with disability, and disability-adjusted life-years for 32 cancer groups, 1990 to 2015: a systematic analysis for the global burden of disease study. JAMA Oncol. 2017;3(4):524-48.
3. Jakovljevic MB, Vukovic M, Fontanesi J. Life expectancy and health expenditure evolution in Eastern Europe-DiD and DEA analysis. Exp Rev Pharmacoecon Outcomes Res. 2016:16(4):537-46.

4. Jakovljevic M, et al. Radiation therapy remains the key cost driver of oncology inpatient treatment. J Med Econ. 2015;18(1):29-36.

5. Jakovljevic $\mathrm{M}$, et al. Costs differences among monoclonal antibodiesbased first-line oncology cancer protocols for breast cancer, colorectal carcinoma and non-Hodgkin's lymphoma. J BUON. 2014;19(4):1111-20.

6. Frazier $\mathrm{AL}$, et al. Cost-effectiveness of screening for colorectal cancer in the general population. JAMA. 2000;284(15):1954-61.

7. Telford JJ, et al. The cost-effectiveness of screening for colorectal cancer. CMAJ. 2010;182(12):1307-13.

8. Vijan S, et al. The cost-effectiveness of CT colonography in screening for colorectal neoplasia. Am J Gastroenterol. 2007;102(2):380-90.

9. Lansdorp-Vogelaar I, Knudsen AB, Brenner H. Cost-effectiveness of colorectal cancer screening. Epidemiol Rev. 2011;33:88-100.

10. Zauber AG, et al. In cost-effectiveness of CT Colonography to screen for colorectal cancer. Rockville; 2009.

11. Kovacevic A, et al. End-of-life costs of medical care for advanced stage cancer patients. Vojnosanit Pregl. 2015:72(4):334-41.

12. Arminski TC, McLean DW. Incidence and distribution of adenomatous polyps of the colon and rectum based on 1000 autopsy examinations. Dis Colon Rectum. 1964;7:249-61.

13. Rickert RR, et al. Adenomatous lesions of the large bowel: an autopsy survey. Cancer. 1979;43(5):1847-57.

14. Vatn $\mathrm{MH}$, Stalsberg $\mathrm{H}$. The prevalence of polyps of the large intestine in Oslo: an autopsy study. Cancer. 1982;49(4):819-25.

15. Regula J, et al. Colonoscopy in colorectal-cancer screening for detection of advanced neoplasia. N Engl J Med. 2006;355(18):1863-72.

16. Strul $\mathrm{H}$, et al. The prevalence rate and anatomic location of colorectal adenoma and cancer detected by colonoscopy in average-risk individuals aged 40-80 years. Am J Gastroenterol. 2006;101(2):255-62.

17. Schoenfeld $P$, et al. Colonoscopic screening of average-risk women for colorectal neoplasia. N Engl J Med. 2005;352(20):2061-8.

18. Lieberman DA, Weiss DG, Veterans G, Affairs Cooperative Study. One-time screening for colorectal cancer with combined fecal occult-blood testing and examination of the distal colon. N Engl J Med. 2001;345(8):555-60.

19. Myers MH, Ries LA. Cancer patient survival rates: SEER program results for 10 years of follow-up. CA Cancer J Clin. 1989;39(1):21-32

20. Selby JV, et al. A case-control study of screening sigmoidoscopy and mortality from colorectal cancer. N Engl J Med. 1992;326(10):653-7.

21. Jorgensen $\mathrm{OD}$, Kronborg $\mathrm{O}$, Fenger $\mathrm{C}$. A randomised study of screening for colorectal cancer using faecal occult blood testing: results after 13 years and seven biennial screening rounds. Gut. 2002;50(1):29-32.

22. Mandel JS, et al. The effect of fecal occult-blood screening on the incidence of colorectal cancer. N Engl J Med. 2000;343(22):1603-7.

23. Greenberg PD, et al. A prospective multicenter evaluation of new fecal occult blood tests in patients undergoing colonoscopy. Am J Gastroenterol. 2000;95(5):1331-8.

24. Imperiale TF, et al. Fecal DNA versus fecal occult blood for colorectalcancer screening in an average-risk population. N Engl J Med. 2004;351(26):2704-14.

25. Collins JF, et al. Accuracy of screening for fecal occult blood on a single stool sample obtained by digital rectal examination: a comparison with recommended sampling practice. Ann Intern Med. 2005;142(2):81-5.

26. Pickhardt PJ, et al. Computed tomographic virtual colonoscopy to screen for colorectal neoplasia in asymptomatic adults. N Engl J Med. 2003;349(23):2191-200.

27. Cotton PB, et al. Computed tomographic colonography (virtual colonoscopy): a multicenter comparison with standard colonoscopy for detection of colorectal neoplasia. JAMA. 2004;291(14):1713-9.

28. Irvine EJ, et al. Prospective comparison of double contrast barium enema plus flexible sigmoidoscopy v colonoscopy in rectal bleeding: barium enema v colonoscopy in rectal bleeding. Gut. 1988:29(9):1188-93.

29. Rex DK. Colonoscopy and acute colonic pseudo-obstruction. Gastrointest Endosc Clin N Am. 1997;7(3):499-508.

30. Levin TR, et al. Complications of colonoscopy in an integrated health care delivery system. Ann Intern Med. 2006;145(12):880-6.

31. Ness RM, et al. Utility valuations for outcome states of colorectal cancer. Am J Gastroenterol. 1999:94(6):1650-7. 
32. Ministry of Health, Ukraine. http://www.moz.gov.ua/ua/portal/regis ter_medicines/. Accessed 15 June 2017.

33. Zauber $A G$, et al. In evaluating test strategies for colorectal cancer screening-age to begin, age to stop, and timing of screening intervals: a decision analysis of colorectal cancer screening for the US preventive services task force from the cancer intervention and surveillance modeling network (CISNET). Rockville; 2009.

34. Sonnenberg A, Delco F, Inadomi JM. Cost-effectiveness of colonoscopy in screening for colorectal cancer. Ann Intern Med. 2000;133(8):573-84.

35. O'Leary BA, et al. Cost-effectiveness of colorectal cancer screening: comparison of community-based flexible sigmoidoscopy with fecal occult blood testing and colonoscopy. J Gastroenterol Hepatol. 2004;19(1):38-47.

36. Norum J. Prevention of colorectal cancer: a cost-effectiveness approach to a screening model employing sigmoidoscopy. Ann Oncol. 1998;9(6):613-8.
37. Ness RM, et al. Cost-utility of one-time colonoscopic screening for colorectal cancer at various ages. Am J Gastroenterol. 2000;95(7):1800-11.

38. De Angelis R, et al. Cancer survival in Europe 1999-2007 by country and age: results of EUROCARE-5-a population-based study. Lancet Oncol. 2014;15(1):23-34

39. Vrdoljak E, et al. Cancer control in central and Eastern Europe: current situation and recommendations for improvement. Oncologist. 2016;21(10):1183-90.

40. Leshno M, Halpern Z, Arber N. Cost-effectiveness of colorectal cancer screening in the average risk population. Health Care Manag Sci. 2003;6(3):165-74.

41. Jakovljevic MB. Resource allocation strategies in Southeastern European health policy. Eur J Health Econ. 2013;14(2):153-9.

Ready to submit your research? Choose BMC and benefit from:

- fast, convenient online submission

- thorough peer review by experienced researchers in your field

- rapid publication on acceptance

- support for research data, including large and complex data types

- gold Open Access which fosters wider collaboration and increased citations

- maximum visibility for your research: over $100 \mathrm{M}$ website views per year

At BMC, research is always in progress.

Learn more biomedcentral.com/submissions 